\title{
0 desamparo adolescente na adolescente contemporaneidade: Contribuições da orientação profissional
}

\author{
The adolescent helplessness in an adolescent contemporaneity: \\ Contributions of vocational guidance
}

Luciana Albanese Valore

Doutora em Psicologia Escolar e do Desenvolvimento Humano pela Universidade de São Paulo (USP), professora associada do Departamento de Psicologia da Universidade Federal do Paraná (UFPR), Curitiba, PR- Brasil, e-mail: luvalore@uol.com.br

Recebido: 06/05/2010 Received: 05/06/2010

Aprovado: 09/12/2010 Approved: $12 / 09 / 2010$

\section{Resumo}

O presente estudo objetiva circunscrever possíveis contribuições da orientação profissional, pensada como estratégia clínica, na lida com o que, no âmbito da adolescência contemporânea, alguns psicanalistas têm denominado de desamparo. Tendo como pressuposto que as transformações vivenciadas por nossa sociedade, particularmente nas relações de e com o trabalho, inauguram novos modos de conviver e novas formas de subjetivação, analisam-se alguns de seus efeitos na configuração da adolescência, na relação jovem-adulto e na construção do futuro. Tal análise, articulada a resultados de pesquisas realizadas no campo da Psicologia Vocacional, embora aponte dificuldades quanto à transição para a vida adulta - dada a condição adolescente da própria ordem social - evidencia o potencial do processo de orientação como ferramenta auxiliar para a superação do sentimento de fragilidade psíquica e de desamparo. Superação esta possível na medida em que a orientação profissional aqui afirmada, dentre outros aspectos, visa a favorecer a mudança na posição subjetiva; ou seja, no modo como o adolescente pode vir a reconhecer-se como sujeito de suas escolhas. Para tanto, entende-se que, conjuntamente à tarefa da escolha, cabe auxiliá-lo no cada vez mais difícil trabalho de tornar-se "gente grande".

Palavras-chave: Adolescência. Contemporaneidade. Orientação profissional. Subjetividade.

\begin{abstract}
This study aims to limit the possible contributions of vocational guidance, designed as a clinical strategy, to deal with something, within the contemporary adolescence, that some analysts have called helplessness. Based on the assumption that the changes experienced by our society, particularly in relationships with and within work, inaugurate new ways of socializing and new forms of subjectivitization, we examine some of its effects on the configuration of adolescence, in young-adult relationship and building of the future. Such analysis, articulated based on the results of research in the field of Vocational Psychology, while pointing out problems regarding the transition to adulthood - given the adolescent condition of the social order itself - highlights the potential of the guidance process as an auxiliary tool for overcoming the feeling of
\end{abstract}


mental weakness and helplessness. Overcoming it is possible to the extent that the vocational guidance asserted here, among other things, aims to promote a change in subjective position; that is, in how the adolescent may come to recognize himself as the subject of his own choices. For such end, it is understood that, together with the task of choosing, it is necessary assisting them in the ever more difficult 'work' of becoming an adult.

Keywords: Adolescence. Contemporaneity. Vocational guidance. Subjectivity.

Muito se tem escrito a respeito das transformações sociais geradas pelas lógicas globais e pelo assim denominado novo capitalismo. Particularmente, no que se refere às relações de e com o trabalho, instigadoras análises, oriundas dos mais diversos campos do saber, têm sido empreendidas no intuito de evidenciar os efeitos de tais transformações na configuração das relações sociais e nos modos de subjetivação contemporâneos. Um desses efeitos diz respeito a uma certa subversão do lugar atribuído à juventude no ideário social, a qual, aliada às condições concretas do mercado de trabalho, implicaria mudanças significativas no processo de transição para a vida adulta.

O presente estudo teórico debruça-se sobre essa questão, fundamentando-se nas reflexões desenvolvidas nos campos da Sociologia, da Psicanálise e da Psicologia Vocacional, com o objetivo de delinear algumas contribuições da prática de orientação profissional, pensada como estratégia clínica (conforme proposta por Bohoslavsky, 1991 e repensada por Torres, 2001), para a superação da condição de fragilidade psíquica e de desamparo atribuída por alguns psicanalistas à adolescência. Para tanto, recorta algumas marcas dos cenários sociais contemporâneos no desenho da adolescência e da relação jovem-adulto, com a finalidade de investigar seus possíveis efeitos no mencionado processo de transição para a vida adulta e, mais precisamente, na elaboração de projetos de futuro. Por fim, a partir da análise das premissas da orientação profissional clínica e dos resultados de pesquisas voltadas à investigação do processo de escolha profissional de adolescentes brasileiros, derivam alguns objetivos para esta prática visando a contribuir para a discussão da questão que tanto tem inquietado educadores e orientadores profissionais, a saber: como orientar num mundo desorientado? (Lehman, 1995; Lassance \& Sparta, 2003).

\section{Cenários profissionais contemporâneos e 0 desenho de uma nova cena subjetiva}

A atual configuração social tem recebido diferentes nomenclaturas: pós-modernidade (Anderson, 1999), sociedade do espetáculo (Debord, 1997), modernidade líquida (Bauman, 2001), hipermodernidade (Lipovetsky, 2007), sociedade de consumo (Baudrillard, 2007); dentre outras. À parte estas divergências, a identificação do que marca o momento histórico atual parece ser unânime entre os autores e consistiria no triunfo do capitalismo e da lógica mercantilista-consumista sobre cada esfera da civilização. Como já dito, além de afetar as relações de (e com o) trabalho, a dominação dessa lógica produziria transformações também no âmbito das relações pessoais, inscrevendo novos modos de convívio e outras formas de subjetivação (Birman, 2000; Bauman, 2001; Lasch, 1983; Oliveira, 2006; Sennett, 2004).

Para caracterizar essa nova ordem social, o sociólogo Richard Sennett (2004) vale-se de uma oposição - sociedade de longo prazo X sociedade de curto prazo - e, diante dela, postula uma tese interessante: a da corrosão do caráter. Para o autor, as mudanças estabelecidas em relação aos requisitos do bom trabalho na atualidade, produziriam, igualmente, mudanças relativas aos requisitos do bom trabalhador e, em última análise, às qualidades de seu caráter. Assim, Sennett irá afirmar que o que outrora foi considerado como sendo bom caráter (algo que exigiria determinação, confiança, lealdade e continuidade nos vínculos interpessoais) não mais se sustentaria na sociedade de redes, onde tudo, inclusive os contatos humanos, passa a ser feito acelerada e sinteticamente, na ânsia de corresponder às exigências da sociedade de curto prazo. 
Nesse contexto, cujo foco residiria no "aqui e agora", a construção de projetos - de vida e de si - de longo prazo não teria mais lugar, tendo em vista que o antigo e previsível esquema de rotina profissional passaria a ser combatido pelo slogan da flexibilidade. Este, ilusoriamente vendido como liberdade na autogestão da carreira, não passaria de uma outra forma de adaptabilidade exigida ao trabalhador: frente à inconstância e incerteza do mercado de trabalho, à crescente necessidade de inovação (de técnicas, produtos e de si mesmo), à demanda de deslocamento de tempo e de lugar, à disponibilidade contínua de correr riscos, à capacidade de atuar performaticamente em várias frentes e em equipes momentâneas de trabalho, à falta de instâncias normativas definidas... Nesta perspectiva ou falta de - restaria ao trabalhador, apenas, a alternativa de aprender a jogar na aleatoriedade. Para tanto, o preço a ser pago consistiria no desapego em relação ao seu trabalho (e às pessoas com quem convive) e no desenraizamento histórico produzido pela efemeridade de suas ações e de si mesmo.

Tal tese vai ao encontro do que Bauman (2001, 2009) denominou de "modernidade líquida", a qual, sinteticamente falando, seria marcada pela liquefação dos valores instituídos pela modernidade sólida, pela exacerbação do consumo, exigência de mobilidade, e legitimação da competitividade, do autocentramento, da indiferença e do medo em relação ao outro. Para o autor, na atualidade, o trabalho deixou de "oferecer o eixo seguro em torno do qual envolver e fixar autodefinições, identidades e projetos de vida" (Bauman, 2001, p. 160). Além disto - poder-se-ia acrescentar - ao centrar-se no registro da satisfação imediata e deixar de ser mensurado pelos efeitos que poderia trazer aos nossos semelhantes e às gerações futuras, o trabalho - ou os vínculos que com ele se poderiam estabelecer - limitar-se-ia ao universo restrito dos "amores líquidos" (Bauman, 2004), em que a mercadoria sempre poderá ser devolvida caso não satisfaça o consumidor.

$\mathrm{Na}$ direção dessas análises, pensadores como Debord (1997), Lasch (1983), Lipovetsky (2007), dentre outros, apontam outras características da contemporaneidade. Dentre elas, a transformação dos sentidos atribuídos às noções de "público" e "privado", a qual resultaria num interessante paradoxo: o esvaziamento e a privatização do espaço público de um lado, a publicização da vida privada de outro. A visibilidade a qualquer preço e o ideal de perfeição (associado ao ideal da eterna juventude) tornar-se-iam, pois, poderosas aspirações a manter a cultura do espetáculo e do narcisismo em que vivemos.

Diante desses cenários, e a considerar a tese freudiana de que tornar-se adulto e manter-se razoavelmente resultam da capacidade de amar e de trabalhar (Freud, 1974), poder-se-ia perguntar a respeito das implicações dos novos modos de ser e conviver no processo de transição para a vida adulta. Afinal, se tanto o amor, como o trabalho, demandam a criação e a preservação de vínculos, que alternativas se apresentam ao adolescente numa sociedade de curto prazo?

\section{A configuração da adolescência na adolescente contemporaneidade}

Nas análises anteriores, é interessante observar que as marcas dos novos tempos, no que se referem ao imediatismo, disponibilidade em correr riscos, volatilidade de interesses e fragmentação identitária, aproximam-se em muito dos atributos usualmente conferidos àquela que se tem configurado, em alguns discursos, como sendo uma etapa do desenvolvimento humano: a adolescência. Paralelamente, a condição de descartável e o correlato imperativo da contínua novidade não deixam de se fazer presentes: quer se destine a objetos, quer se refira a pessoas, a exigência de manter-se (ou de parecer) eternamente jovem tornou-se palavra de ordem. Basta ver os apelos publicitários para constatar tal afirmação. De certo modo, poder-se-ia considerar, numa extensão do termo e do sentido, que estamos todos vivendo uma "crise de identidade", a qual, a julgar pelo contexto, deverá ser perene, dada a impossibilidade de constituição de um si que, ao longo do tempo, permanece idêntico a si mesmo (Lehman, 2010). Isto considerado, no presente escrito, permitiu-se qualificar a contemporaneidade (em seus modos de viver e conviver) como adolescente.

Importante lembrar que os sentidos atribuídos à adolescência mudam conforme os tempos e o ideário social. Para compreendê-los na atualidade pode ser produtivo acompanhar a reflexão desenvolvida por Calligaris (2000, p. 9). Nas palavras do autor:

a adolescência é o prisma pelo qual os adultos olham os adolescentes e pelo qual os próprios adolescentes 
se contemplam. Ela é uma das formações culturais mais poderosas de nossa época. Objeto de inveja e de medo, ela dá forma aos sonhos de liberdade ou de evasão dos adultos, a seus pesadelos de violência e desordem. Objeto de admiração e ojeriza, ela é um poderoso argumento de marketing e, ao mesmo tempo, uma fonte de desconfiança e repressão preventiva.

Assim, se até meados dos anos 1960, a idade adulta consistia no ideal dos adolescentes (ávidos em vestirem-se e portarem-se como adultos, em aventurarem-se em experiências restritas ao universo dos mais velhos, não a eles se conformando, mas também não deles se diferenciando por serem infantis, adolescentes), hoje, a adolescência tornou-se o ideal dos adultos (ávidos em vestirem-se e portarem-se como adolescentes, em aventurarem-se em experiências restritas ao universo dos mais novos, a eles se conformando e deles não se diferenciando como adultos). Essa curiosa inversão, derivada da exigência de eterna juventude, gera uma ambiguidade: ansioso por ser tratado em "pé de igualdade" com seus pares sociais adultos e por desfrutar das prerrogativas de "gente grande", o jovem acabaria por deparar-se com um movimento contrário ao seu, de retorno àquela fase da qual aspira subtrair-se. Ou, como bem observa Calligaris (2000, p. 74): "Os adolescentes pedem reconhecimento e encontram no âmago dos adultos um espelho para se contemplar. Pedem uma palavra para crescer e ganham um olhar que admira justamente o casulo que eles queriam deixar".

Ao encarnar os ideais de supostas liberdade e felicidade, tão caros à sociedade contemporânea, a adolescência passaria a encerrar exigências inconciliáveis: a de continuar sendo, indefinidamente, adolescente - o que contraria, totalmente, as expectativas que o jovem poderia ter de ser reconhecido como adulto - e a de assumir as responsabilidades de adulto, num contexto em que os próprios adultos as rechaçam. Tal reviravolta não deixa de ter consequências. Uma delas reside na diluição do conflito de gerações (Birman, 2000, 2006; Jerusalinsky, 2000; Paladino, 2005) sustentada pela ilusão de simetria de posições na relação jovem-adulto.

Sayão e Aquino (2007) ratificam tal tese em sua leitura da relação pais e filhos na atualidade. Ao discorrerem sobre o enxugamento da família, evidenciam seus vários efeitos: o isolamento de crianças e jovens, cuja socialização ficaria restrita à convivência na escola; sua superproteção e consequente fragilização, derivada da crença dos pais de que seriam os únicos a tutelar o ingresso na vida adulta; a solidão afetiva e o sentimento de abandono, como produtos do isolamento das famílias e do desejo de extensão imaginária dos pais outorgado aos filhos; a dependência e o medo de errar, decorrência do medo dos pais de perderem o amor de seus filhos e de sua exigência de perfeição e de constante superação deles mesmos; a intolerância à frustração, diretamente proporcional ao desejo paterno de que ao filho nada falte... E o mais grave de todos: o sentimento de orfandade produzido pela disputa do lugar de jovem com o próprio filho.

Nas reflexões desenvolvidas por psicanalistas que se voltam ao estudo da adolescência contemporânea, tal sentimento de orfandade é reconhecido como desamparo. Este, embora constitutivo da condição humana, seria potencializado pela escassez de referenciais, pela precariedade de ideais e pela ilusão de perfeição ou completude próprias do contexto atual. Como colocam Palmeira, Mayerhoffer, Mariz e Cardoso (2006, p. 160): "Ante o ideal contemporâneo de ser completo, a cultura parece negar um lugar para a angústia ou a solidão, como se estas não existissem. Diante disso, o jovem se vê perdido, imobilizado em um mundo "hostil' e sem direção". Ademais, cabe destacar o sentimento de desamparo da família diante da tarefa educativa. Segundo as autoras, a dificuldade de impor limites, articulada a outros fatores, contribui para a intolerância frente às perdas e frustrações e para a incapacidade de criar e fantasiar, limitando, consideravelmente, a possibilidade de simbolização da falta.

Ao discorrer sobre o prolongamento da adolescência, e o correlato enxugamento da infância, na atualidade, Birman (2006) corrobora estas afirmações, demonstrando como o empobrecimento das relações de troca, o aumento da rivalidade entre os pares e a superproteção familiar acabaram por inscrever a solidão no universo infanto-juvenil, produzindo a fragilização psíquica e potencializando o sentimento de desamparo. Em tais condições, como observa o autor, não é de espantar que a cultura das drogas e da violência se imponham como marcas da juventude contemporânea: imersos na ilusão de que "podem tudo" reagem com destrutividade (auto ou hetero) à percepção de "não poder fazer nada". Evidentemente, isto tudo - associado às precárias condições de inserção no mercado de trabalho, ao 
aumento da criminalidade e da desconfiança em relação ao semelhante, ao esgotamento dos recursos naturais - afeta, de maneira significativa, a construção de projetos de vida:

diante da falta de horizonte de futuro e na posição infantilizada em que se situa hoje, a juventude se inscreve decididamente na cultura do espetáculo que perpassa a cultura contemporânea. Assim, todos querem ser celebridades e ocupar a cena midiática como protagonistas importantes e até mesmo como pop stars, como contrapartida onipotente para a impotência vertiginosa em que estão lançados (Birman, 2006, p. 41).

Frente a este quadro, não muito promissor, em que o olhar sobre a descendência desaloja o valor da ascendência e em que as experiências de alteridade escasseiam, como ser reconhecido como adulto? Numa sociedade imediatista, competitiva, violenta, que não valoriza as tradições tampouco oferta chances efetivas de inserção no mundo adulto, uma "sociedade da decepção" (Lipovetsky, 2007) - que produz passividade e apatia pela satisfação imediata de todos os desejos -, qual seria a senha para entrar no mundo adulto e que vantagens esse mundo teria a oferecer? Como pensar em projetos de vida, calcados na continuidade e no exercício de uma profissão e num si pensados para "toda a vida", quando os projetos, assim como as pessoas, tornam-se rapidamente obsoletos e descartáveis?

\section{Superando o desamparo adolescente: contribuições da orientação profissional na estratégia clínica}

Pesquisas nacionais desenvolvidas com estudantes do ensino médio público e privado evidenciam o privilegiamento conferido ao trabalho e à condição de estabilidade financeira-emocional no projeto de vida futura (Sarriera, Silva, Kabbas \& Lopes, 2001; Paredes \& Pecora, 2004; Coutinho, Insfrán, Peixoto, Gomes, Backes, Carvalho, et al., 2005; Nascimento, 2006; Zonta, 2007; Valore \& Viaro, 2007; Marcelino, Catão, \& Lima, 2009; Graf \& Diogo, 2009). Quer mostrada como oportunidade de melhoria de vida e de ascensão social (especialmente no discurso de jovens provenientes da escola pública), quer encenada como possibilidade de realização pessoal (com menor frequência e, quando enunciada, majoritariamente por alunos da rede privada), a inserção laboral (por meio da obtenção de um "bom emprego" - leia-se rentável) aparece em destaque como consequência natural de uma boa qualidade de estudo (superior, de preferência) e como requisito para a constituição de uma família (segundo elemento mais frequente nos projetos de vida analisados). De certo modo, tais dados, ainda que indiquem uma incorporação dos valores contemporâneos, no que se refere à primazia dada à satisfação material e ao consumismo, não deixam de acenar com uma certa resistência aos modos de viver analisados anteriormente, na medida em que "teimam" em se constituir como projetos lineares, estáveis e de longo prazo. Isto considerado, poder-se-ia perguntar: faz sentido atribuir à atual adolescência a condição de desamparo?

Um modo de pensar a questão seria supor, com Coutinho et al. (2005), que o ideal de estabilidade (no trabalho e na família) seria a única saída possível para a situação de sofrimento e exclusão social vivenciada por jovens das camadas economicamente mais vulneráveis. Contudo, considerando-se que este ideal estrutura igualmente os projetos de vida de jovens com maior poder aquisitivo, poder-se-ia estender essa hipótese supondo que a busca pela estabilidade configuraria uma tentativa de superação do sentimento de insegurança gerado pela percepção da falência de algumas práticas institucionais e pela incerteza que marcam o viver contemporâneo. E que, a julgar pelas dificuldades assinaladas pelos estudiosos do tema quanto à manutenção de projetos de longo prazo, os jovens estejam efetivamente desamparados. Entendemos, porém, que tais afirmações mereceriam uma análise mais abrangente (abarcando outros aspectos, além do projeto de vida, e outras populações, como a de jovens excluídos do sistema educacional, por exemplo), com vistas a resultados mais conclusivos. Ainda assim, com base nos relatos de orientadores profissionais e em minha própria experiência (como supervisora de estágios nessa área), acreditamos que a condição de desamparo pode ser pensada em relação à situação enfrentada pela maioria dos adolescentes brasileiros no processo de escolha de uma profissão e de construção de um projeto de vida. Vejamos por quê.

Um aspecto recorrente identificado na literatura que trata da escolha profissional de estudantes de ensino médio refere-se ao pouco conhecimento, ou às informações idealizadas ou distorcidas, sobre as profissões e sobre a realidade do mercado 
de trabalho, em suas oportunidades e novas exigências (Ribeiro, 2003; Sarriera \& Shiessl, 2004; Sparta, Bardagi \& Andrade, 2005; Sparta \& Gomes, 2005; Soares, Krawulski, Dias \& D’Avila, 2007, dentre outros). Tal fato, associado à falta de investimento no autoconhecimento e na articulação deste com o conhecimento da realidade ocupacional, não raro, encontra-se relacionado aos altos índices de evasão no ensino universitário e sinalizam a falta de preparo dos estudantes quanto ao planejamento de sua vida futura.

De modo geral, as pesquisas nacionais na área evidenciam aquilo que Sparta, Bardagi \& Andrade (2005) configuram como um padrão pobre de exploração vocacional, caracterizado por uma busca pouco sistemática de informações sobre si e sobre o mundo de trabalho. Frente a esta realidade, fazendo coro aos demais pesquisadores da área, as autoras concluem pela necessidade de aproximar a educação do mundo do trabalho, implicando a escola em projetos mais amplos de educação para a carreira (já efetivados em outros países). Tal iniciativa, acreditamos, configuraria uma produtiva estratégia de superação da condição de desamparo, ou de abandono, em que a maior parte dos adolescentes se encontra no momento de decidir o que fazer, agora que "já cresceu". Outra possibilidade, parece-nos, reside nas contribuições que um processo de orientação profissional, pensada como estratégia clínica, pode oferecer a quem nele se disponha a implicar. Antes de discorrer a respeito, entretanto, convém deixar claro que, embora referida como estratégia clínica, a orientação aqui considerada não se limita ao trabalho desenvolvido em consultório, podendo ser levado a cabo em outros contextos. Como se verá a seguir, o termo "clínica" refere-se a um modo de escuta e não a um local de intervenção.

Não obstante tenha sido Bohoslavsky (1991) a propor o uso de tal estratégia na prática da orientação profissional (OP), a perspectiva aqui adotada encontra maior ressonância na proposta de Torres (2001), uma vez que se fundamenta na teoria freudiana e não no referencial kleiniano adotado pelo autor. Mesmo assim, de seus escritos, resgatam-se algumas proposições:

1) o termo "clínica" refere-se a uma estratégia de abordagem do objeto de estudo - no caso, o comportamento vocacional - a qual implica um processo contínuo de articulação entre investigação e intervenção. Além disto, remete a uma "visão particularizante, que considera cada situação como singular, peculiar" (Bohoslavsky, 1991, p. 37), sem ser de cunho individual, posto que considera a singularidade como algo que se constitui em meio a relações sociais;

2) no processo anteriormente mencionado a presença do orientador, ou melhor, sua subjetividade, altera o campo de observação; i. é: tal subjetividade não deve ser excluída dos resultados obtidos, ao contrário, ela contribui para a sua produção;

3) a orientação profissional insere-se numa dimensão ética. Nas palavras do autor: "A ética surge do fato de que, ao considerar o homem sujeito de escolhas, consideraremos que a escolha do futuro é algo que lhe pertence e que nenhum profissional, por mais capacitado que esteja, tem o direito de expropriar" (Bohoslavsky, 1991, p. 47);

4) para um adolescente, a tarefa de construir o futuro não consiste apenas em definir "o que" fazer, mas, principalmente, em definir "quem" ser e, ao mesmo tempo, quem deixar de ser;

5) a escolha profissional relaciona-se a condições concretas de vida e a condições subjetivas (conscientes e inconscientes). Nestas, destacam-se as identificações desenvolvidas vida adentro.

Dessas proposições permitimo-nos derivar alguns nortes para a prática da OP pensada como ferramenta auxiliar na superação da condição de desamparo presente na adolescência contemporânea:

1) Acolher o orientando, sem direcioná-lo para algo que se considere como sendo sua escolha ideal (desenhada no imaginário do orientador), estimulando-o a falar de si e, principalmente, a escutar aquilo que diz e a escutar-se naquilo que diz;

2) Respeitar - e suportar - seu tempo de escolha e eventual desejo de não fazê-la;

3) Propiciar uma escolha madura que vá além de uma escolha ajustada, pois considera a elaboração dos lutos e conflitos (muitas vezes inconscientes) que permeiam o processo de escolha. Além disto, essa escolha deverá ser "prospectiva, pessoal, autônoma, responsável e independente" (Bohoslavsky, 1991, p. 89); 
4) Auxiliar o orientando a tornar-se, ou reconhecer-se sujeito de suas escolhas, autor de seu projeto de vida (com o correlato conhecimento dos fatores que motivam suas decisões e a consequente responsabilização pelas mesmas);

5) Ajudá-lo a reconhecer os elementos que estruturam seu projeto de vida (ainda que, a princípio, ele nos diga que "nunca pensou nisso!"), suas expectativas e temores quanto ao futuro, de forma a contribuir para a visualização de estratégias, quer para o enfrentamento das eventuais dificuldades, quer para o planejamento de suas ações;

6) Instrumentalizá-lo para o conhecimento (e não mera informação) da realidade ocupacional (especialmente em suas novas demandas), incentivando-o no trabalho de pesquisa, sempre lembrando que tal realidade será por ele apropriada e continuamente ressignificada de modo singular (ou seja, não há uma realidade absoluta e homogênea a ser assimilada, de igual maneira, por todos os orientandos);

7) Favorecer a reflexão sobre as transformações no mundo do trabalho e nas relações sociais de modo geral, no intuito de contribuir para a sua tomada de decisões e para a construção de um seu posicionamento frente às mesmas;

8) Auxiliá-lo na configuração de sua identidade vocacional (quem ele quer ser e quem irá deixar de ser nesse mundo em contínua transformação);

9) Configurar-se como um trabalho psicoprofilático, na medida em que se volta à aprendizagem da escolha e ao exercício de auto-observação como tarefas a serem empreendidas em futuras situações de escolha.

Tais nortes poderiam ser sintetizados na compreensão de Torres (2001, p. 52) acerca do processo de OP:

um trabalho que visa a favorecer este momento de escolha, por meio da reflexão acerca de si mesmo e da situação em que se encontra, vislumbrando aspectos de natureza psicológica e informativa. É um processo que consiste em criar condições para que o sujeito que dela necessita possa situar-se enquanto sujeito dele, exercendo o seu pensar, seu refletir, informando-se e elaborando questões relativas a esse assunto. Assim, terá condições de construir um projeto pessoal mais consciente e que inclua os elementos da realidade sociopolítica e econômica.

Atribuir à OP a qualificação de ferramenta "auxiliar" na superação do desamparo deriva da percepção de que, evidentemente, uma orientação só "não faz verão"... Brincadeira à parte, nunca é demais lembrar que o desamparo será sempre produto de um contexto relacional; sua superação, portanto, resultaria de um esforço coletivo no sentido de alterar a correlação de forças que vão muito além da prática de orientação (condições do mercado de trabalho, práticas educativas, ideário social, etc.). Ainda assim, apostamos em suas contribuições tendo em vista, sobretudo, sua tarefa de incentivar e instrumentalizar a construção de um projeto de vida (e não apenas a escolha de uma profissão). $\mathrm{E}$, considerando-se que o projeto de vida sustenta-se no conjunto de atributos que define o sujeito, no valor e no poder que atribui a si, aos outros e ao mundo (Nascimento, 2006), apostamos, igualmente, em sua tarefa (da OP) de favorecer a construção de um si que poderá vir a reconhecer-se como autor desse projeto.

Para tanto, em se tratando de adolescentes, pensamos que, ao ser desenvolvida em grupo, a OP ofereça maiores oportunidades para o compartilhamento de experiências, receios e angústias e para a circulação de discursos, promovendo uma situação de amparo aos orientandos. No que se refere a procedimentos, acreditamos que as técnicas de autoconhecimento e de informação ocupacional usualmente adotadas nas práticas de orientação (independentemente de terem uma perspectiva psicanalítica) podem vir em auxílio. Na perspectiva aqui adotada, porém, e tendo como pressuposto que a construção da subjetividade se dá nas relações discursivas, privilegia-se como método a análise dos discursos (Guirado, 2009): de todos os discursos (e não apenas os produzidos numa situação de entrevista individual) enunciados ao longo do processo. Estes, certamente, remetem a uma ordem discursiva que, embora atravesse as falas de orientandos e orientador, as extrapola (discursos sociais sobre trabalho, vida adulta, sucesso, educação, adolescência, etc.). 
A ênfase dada à intervenção psicanalítica, no âmbito da OP, como análise de discursos ${ }^{1}$ requer que algumas perguntas sejam feitas - tanto a título de diagnóstico, como da própria orientação - durante o processo contínuo e articulado de investigação-intervenção. Assim, pode ser produtivo questionar que ideias e ideais configuram a escolha e o projeto de vida do adolescente, em que ele os sustenta (e em que medida os percebe como estando articulados aos discursos sociais instituídos), quais são suas expectativas e seus temores em relação ao futuro, que lugar se atribui neste futuro, como imagina que os outros o veem, o que espera de si e o que acredita que esperam dele, como vê a vida adulta e como se imagina como adulto, que recursos imagina serem necessários para a concretização de seu projeto de vida e assim por diante. Importa também indagar como vê o mundo em que vive, como o imagina no futuro, em que medida incorpora ou resiste aos novos padrões, que lugar atribui ao trabalho em sua vida... Enfim, vários podem ser os aspectos sobre os quais o adolescente poderá ser convidado a falar (e a se escutar). 0 mais importante, parece-nos, é atentar aos lugares atribuídos (a si, aos outros, ao trabalho, ao futuro) em seu discurso e ao modo como se posiciona diante da tarefa de OP e das expectativas que lhe são depositadas, de maneira que possa legitimá-los ou transformá-los (a esses lugares e expectativas).

Entendemos que, deste modo, a OP também possa se constituir como um espaço de produção de novos sentidos para crenças, pressupostos e discursos cristalizados e naturalizados auxiliando o orientando, "no movimento contínuo do olhar, sentir, dizer e escutar (sobretudo a si próprio), de dentro para fora e de fora para dentro" (Valore, 2010, p. 74), a tomar posição. Com isto, espera-se que ele possa se perceber como agente - e não somente mero espectador - tanto de sua própria história, como do contexto em que vive. A OP, assim praticada, ao incentivar e instrumentalizar, a/para a ocupação desse lugar, poderá propiciar condições para a superação da "fragilidade psíquica" ou "infantilização". Por fim, ao se constituir como um exercício de paciência, frente ao inevitável e demorado trabalho de "costura" entre o passado, o presente e o futuro, e como um rico aprendizado (a ser levado vida afora) de tolerância frustração diante da ausência de respostas prontas para o rápido consumo, a OP também poderá contribuir para o desenvolvimento de uma maior autoconfiança - requisito necessário para a superação do sentimento de desamparo.

\section{Considerações finais}

A análise dos cenários sociais contemporâneos, no discurso de seus estudiosos, parece não deixar dúvida: as lógicas do mercado, cada vez mais determinantes dos novos modos de viver e conviver, não preveem qualquer garantia de continuidade, seja para os projetos de vida, seja para a própria identidade. A necessidade de estabelecer metas a curto prazo, de apresentar-se como alguém flexível, continuamente disposto a correr riscos, associada aos apelos do hiperconsumo e à "liquidez" dos ideais norteadores do viver em sociedade, instituem novos horizontes para as aspirações pessoais, em meio ao desenho de uma outra cena subjetiva. Nesta, a condição adolescente, como vimos, ocupa lugar de ideal no imaginário social, dificultando, sobremaneira, a transição para a vida adulta e instaurando o sentimento de desamparo. Tal reviravolta, todavia, conforme atestam estudos na área, parece não ter sido totalmente incorporada no discurso daqueles que, convidados a descreverem seus planos para o futuro, elegem o trabalho (geralmente imaginado como "emprego rentável" e "para toda a vida") como meio que irá garantir a felicidade futura.

De um lado, precariedade e instabilidade; de outro, 0 anseio juvenil por estabilidade. 0 imperativo da "eterna juventude" e a exigência de que os adolescentes se tornem adultos. Um tempo de incertezas e de homens incertos e a expectativa de "um homem certo para o lugar certo"... Efetivamente, não são poucos os desafios que se colocam ao orientador profissional dessa adolescente contemporaneidade; afinal, que sentido poderia haver em orientar para um mundo que vem se mostrando tão desorientado?

Em que pese o sentimento de impotência que a análise dos cenários contemporâneos possa provocar, acreditamos no potencial da OP, pensada como estratégia clínica, como ferramenta auxiliar na superação do desamparo adolescente na construção

\footnotetext{
1 Para um aprofundamento dessa tese remete-se o leitor à obra de Guirado, 2009.
} 
de projetos de vida e na transição para a vida adulta. Superação esta possível, na medida em que a orientação profissional aqui afirmada foca sua atenção na posição subjetiva, no modo como o orientando se vê e se posiciona diante de suas escolhas, de sua vida passada, presente e futura. Com isso, espera-se, poderá auxiliá-lo a reconhecer-se e assumir-se como um sujeito de escolhas.

Assim, mesmo que o desamparo seja constitutivo da condição humana (como o postulam os psicanalistas) e que o adolescente tenha que encontrar seu próprio modo de lidar com isto, a complexa tarefa de "tornar-se gente grande" não deveria ser empreendida de forma solitária. Nisso vislumbramos uma importante contribuição da orientação profissional. Tal contribuição, todavia, se dá na tensão com o desafio de sair ela mesma, a OP, da condição de desamparo. Dito de outro modo, se nada se pode fazer sozinho frente à condição de desamparo (posto que isso dependeria de uma série de transformações sociais, como uma nova dinâmica do mercado de trabalho, de forma a ampliar a oportunidade de inserção profissional aos jovens em busca do primeiro emprego; um maior respaldo das instituições educativas com vistas à aproximação com o mundo do trabalho; e uma mudança na postura "adulta", de modo que viesse a exercer, efetivamente, o lugar de adulto), algo se pode propor diante do sentimento de desamparo e a OP seria uma alternativa. Entretanto, a ela articulada, seriam necessárias outras ações que colocassem em movimento também as engrenagens sociais que têm instituído os modos de viver contemporâneos, a fim de convocá-las - ou a seus agentes - a refletir e a agir sobre suas implicações (entendidas aqui como efeitos e como compromissos) no processo de transição para a vida adulta.

\section{Referências}

Anderson, P. (1999). As origens da pós-modernidade. Rio de Janeiro: J. Zahar.

Baudrillard, J. (2007). A sociedade de consumo. Lisboa: Edições 70.

Bauman, Z. (2001). Modernidade líquida. Rio de Janeiro: J. Zahar.

Bauman, Z. (2004). Amor Líquido: Sobre a fragilidade dos laços humanos. Rio de Janeiro: J. Zahar.
Bauman, Z. (2009). A arte da vida. Rio de Janeiro: J. Zahar.

Birman, J. (2000). Mal-estar na atualidade: A psicanálise e as novas formas de subjetivação (2a ed.). Rio de Janeiro: Civilização Brasileira.

Birman, J. (2006). Tatuando o desamparo. In M. R. Cardoso (Org.). Adolescentes (pp. 25-43). São Paulo: Escuta.

Bohoslavsky, R. (1991). Orientação vocacional: A estratégia clínica (8a ed.). São Paulo: M. Fontes. (Original publicado em 1979).

Calligaris, C. (2000). A adolescência. São Paulo: Publifolha.

Coutinho, L. G., Insfrán, F. F. N., Peixoto, M. V., Gomes, R. M., Backes, J. C., Carvalho, H. P., et al. (2005). Ideais e identificações em adolescentes de Bom Retiro. Psicologia \& Sociedade, 17(3), 33-39.

Debord, G. (1997). A sociedade do espetáculo. Rio de Janeiro: Contraponto. (Original publicado em 1967).

Freud, S. (1974). O mal estar na civilização. Rio de Janeiro: Imago. (Original publicado em 1930).

Guirado, M. (2009). A análise institucional do discurso como analítica da subjetividade. São Paulo: Annablume, 2010.

Graf, L. P., \& Diogo, M. F. (2009). Projeções juvenis: Visões ocupacionais e marcas de gênero. Revista Brasileira de Orientação Profissional, 10(1), 71-82.

Jerusalinsky, A. (2000). Papai não trabalha mais. In A. Jerusalinsky. 0 valor simbólico do trabalho e o sujeito contemporâneo. (pp. 35-49). Porto Alegre: Artes \& Ofícios.

Lasch, C. (1983). A cultura do narcisismo. Rio de Janeiro: Imago.

Lassance, M. C., \& Sparta, M. (2003). A orientação profissional e as transformações no mundo do trabalho. Revista Brasileira de Orientação Profissional, 4 (1-2), 13-19.

Lehman, Y. P. (1995). O papel do orientador profissional - revisão crítica. In A. M. B. Bock (Org.). A escolha profissional em questão (pp. 239-246). São Paulo: Casa do Psicólogo.

Lehman, Y. P. (2010). Orientação profissional na pós-modernidade. In R. S. Levenfus \& D. H. P. Soares (Org.). Orientação vocacional ocupacional (pp. 19-30). Porto Alegre: Artmed. 
Lipovetsky, G. (2007). A sociedade da decepção. São Paulo: Manole.

Marcelino, M. Q. S., Catão, M. F. F. M., \& Lima, C. M. P. (2009). Representações sociais do projeto de vida entre adolescentes do ensino médio. Psicologia: Ciência e Profissão, 29(3), 544-557.

Nascimento, I. P. (2006). Projeto de vida de adolescentes do ensino médio: Um estudo psicossocial sobre suas representações. Imaginário, 12(12), 55-80.

Oliveira, S. R. B. C. (2006). Indiferença, o esquecimento do humano: Um estudo sobre a importância dos "espaços de fala" entre os jovens no contemporâneo. Dissertação de Mestrado não publicada, Universidade Federal do Rio de Janeiro, Rio de Janeiro.

Paladino, E. (2005). 0 adolescente e o conflito de gerações na sociedade contemporânea. São Paulo: Casa do Psicólogo.

Palmeira, C. G., Mayerhoffer, E. L., Mariz, N. N., \& Cardoso, M. R. (2006). Desamparo e melancolia na adolescência contemporânea. In M. R. Cardoso, (Org.). Adolescentes (pp. 157-168). São Paulo: Escuta.

Paredes, E. C., \& Pecora, A. R. (2004). Questionando o futuro: As representações sociais de jovens estudantes. Psicologia: Teoria e Prática, 6(3), 49-65.

Ribeiro,M.A.(2003).Demandasemorientaçãoprofissional: Um estudo exploratório em escolas públicas. Revista Brasileira de Orientação Profissional, 4(1-2), 141-151.

Sarriera, J. C., Silva, M. A., Kabbas, C. P., \& Lopes, V. B. (2001). Formação da identidade ocupacional em adolescentes. Estudos de Psicologia, 6(1), 27-32.

Sarriera, J. C., \& Schiessl, C. S. (2004). Refletindo a questão do ingresso ao ensino superior: Dificuldades e expectativas dos jovens de ensino médio. In J. C. Sarriera (Org.). Desafios do mundo do trabalho: Orientação, inserção e mudanças (pp. 33-71). Porto Alegre: EDIPUCRS.
Sayão, R., \& Aquino, J. R. G. (2007). Família: Modos de usar. (2a ed.). Campinas: Papirus.

Sennett, R. (2004). A corrosão do caráter. (8a ed). Rio de Janeiro: Record.

Soares, D. H. P., Krawulski, E., Dias, M. S. de L., \& D’Avila, G. T. (2007). Orientação profissional em contexto coletivo: Uma experiência em pré-vestibular popular. Psicologia, Ciência e Profissão, 27(4), 746-759.

Sparta, M., Bardagi, M. P., \& Andrade, A. M. J. (2005). Exploração vocacional e informação profissional percebida em estudantes carentes. Aletheia, 22(2), 79-88.

Sparta, M., \& Gomes, W. (2005). Importância atribuída ao ingresso na educação superior por alunos do ensino médio. Revista Brasileira de Orientação Profissional, 6(2), 45-53.

Torres, M. L. C. (2001). Orientação profissional clínica: Uma interlocução com conceitos psicanalíticos. Belo Horizonte: Autêntica.

Valore, L. A. (2010). Orientação Profissional em grupo na escola pública: Direções possíveis, desafios necessários. In R. S. Levenfus \& Dulce H. P. Soares (Org.). Orientação vocacional ocupacional (pp. 65-81). Porto Alegre: Artmed.

Valore, L. A., \& Viaro, R. V. (2007). Profissão e sociedade no projeto de vida de adolescentes em orientação profissional. Revista Brasileira de Orientação Profissional, 8(2), 57-70.

Zonta, G. A. (2007). A construção do projeto de vida do aluno da rede pública de educação. Psicologia Argumento, 25(50), 261-268. 